Для цитирования: Иванов Н.А., Кожушкина И.В., Оборин М.С., Шерешева М.Ю. Разработка характеристик институциональной среды с иелью моделирования устойчивого развития территорий. Вестник Дагестанского государственного технического университета. Технические науки. 2017; 44 (3):185-198. DOI:10.21822/2073-61852017-44-3-185-198

For citation: Ivanov N.A., Kozhushkina I.V., Oborin M.S., Sheresheva M.Yu. Development of the characteristics of the institutional environ-ment for the modeling of sustainable development of regions. Herald of Daghestan State Technical University. Technical Sciences. 2017; 44 (3): 185-198. (In Russ.) DOI:10.21822/2073-6185-2017-44-3-185-198

\title{
ЭКОНОМИЧЕСКИЕ НАУКИ
}

\section{УДК 338.48}

DOI: $10.21822 / 2073-6185-2017-44-3-185-198$

\section{РАЗРАБОТКА ХАРАКТЕРИСТИК ИНСТИТУЦИОНАЛЬНОЙ СРЕДЫ С ЦЕЛЬЮ МОДЕЛИРОВАНИЯ УСТОЙЧИВОГО РАЗВИТИЯ ТЕРРИТОРИЙ}

\author{
Иванов Н.А. ${ }^{3}$, Кожсуикина И.В. ${ }^{4}$, Оборин М.С. ${ }^{1}$, Нерешева М.Ю. ${ }^{2}$, \\ ${ }^{1}$ Пермский институт (филиал) \\ Российский экономический университет им. Г.В. Плеханова, \\ ${ }^{1}$ Пермский государственный национальныий исследовательский университет, \\ ${ }^{1} 614070$, г. Пермь, ул. Бульвар Гагарина, 57, Россия, \\ ${ }^{1} 614990$, г. Пермь, ул. Букирева, 15, Россия, \\ ${ }^{2-3}$ Московский государственный университет им. М.В.Ломоносова, \\ 2-3 119991, г. Москва, Ленинские горы, д.1-46, Россия, \\ ${ }^{4}$ Сочинский государственный университет, \\ ${ }^{4}$ 354000, г. Сочи, ул. Советская, 26а, Россия, \\ ${ }^{1}$ e-mail: recreachin@ rambler.ru, ${ }^{2}$ e-mail:m.sheresheva@gmail.com, \\ ${ }^{3}$ e-mail: $\underline{\text { n.a.ivanov33@gmail.com, }}{ }^{4}$ e-mail:kojushkina@yandex.ru
}

Резюме: Цель. Целью исследования является разработка характеристик институциональной среды, обеспечивающих устойчивое развитие территорий. Методы. Методами исследования являются системный анализ, сочиально-экономическое моделирование и прогнозирование. В иелях наглядного изображения аналитических данных и авторских результатов использован метод графических изображений. Результат. Обоснована актуальность устойчивого развитий территорий в современных экономических условиях, выявлена необходимость комплексного подхода к выбору экономических, сочиальных и экологических критериев для реализачии программ, направленных на преобразование социально-экономического пространства территорий, мальх городов, муниципальных образований. Выявлена роль институтов в развитии территорий, рассмотрень их механизмы и классификации. Охарактеризованы различные подходы ученых к раскрытию роли и значимости институциональной среды, необходимости ее модернизации и адаптации к настоящим условиям функционирования экономики. Проведен анализ сочиально-экономических характеристик институциональной среды, определень направления их формирования до уровня, соответствующего стратегии развития территории, малого города, мунищипального образования. Охарактеризованы показатели развития институцииональной среды мальх городов на примере трех субъектов РФ: Пермский край, Тульская, Владимирская области. Проанализирован состав институтов бизнес-среды, образования, культуры и спорта. Отражены данные о бюджетных показателях мальх городов рассматриваемых субъектов, выявлены проблемы дефицита местных бюджетов в большинстве муниципальных образований. Вывод. На основе выявленных направлений и критериев развития институциональной среды разработаны направления моделирования устойчивого развития территорий. 
Статья выполнена при финансовой поддержке гранта Российского научного фонда (проект № 17-18-01324) «Устойчивое развитие экономики территорий на основе сетевого взаимодействия мальх городов и районных иентров».

Ключевые слова: институцииональная среда, устойчивое развитие, территория, моделирование

\title{
ECONOMIC SCIENCE
}

\section{DEVELOPMENT OF THE CHARACTERISTICS OF THE INSTITUTIONAL ENVIRONMENT FOR THE MODELING OF SUSTAINABLE DEVELOPMENT OF REGIONS}

\author{
Nikolay A. Ivanov ${ }^{3}$, Irina V. Kozhushkina , Matvey S. Oborin ${ }^{1}$, Marina Yu. Sheresheva ${ }^{2}$ \\ ${ }^{1}$ Perm Institute (branch) of Plekhanov Russian University of Economics, \\ ${ }^{1} 57$ Gagarin Boulevard, Perm 614070, Russia, \\ ${ }^{1}$ Perm State University, \\ ${ }^{1} 15$ Bukireva Str., Perm 614990, Russia, \\ ${ }^{2-3}$ Lomonosov Moscow State University, \\ 1-46 Leninskiye Gory, Moscow 119991, Russia, \\ ${ }^{4}$ Sochi State University, \\ 26 a Sovetskaya Str., Sochi 354000, Russia, \\ ${ }^{1}$ e-mail: recreachin@ rambler.ru, ${ }^{2}$ e-mail:m.sheresheva@gmail.com, \\ 3 e-mail: $\underline{\text { n.a.ivanov33@gmail.com, }}{ }^{4}$-mail:kojushkina@yandex.ru
}

Abstract Objectives. The aim of the study is to develop the characteristics of the institutional environment to ensure the sustainable development of regions. Methods. Research methods comprise the system analysis, socio-economic modelling and forecasting. The method of graphic images is used in order to visualise the analytical data and the results. Results. The relevance of sustainable regional development in the current economic conditions is substantiated, the necessity of a complex approach of economic, social and ecological criteria for the implementation of programmes aimed at transforming the social and economic space of territories, small towns, and municipalities is identified. The role of institutions in the development of territories is revealed and their mechanisms and classifications examined. Different scientific approaches to the role and significance of the institutional environment are characterised alongside a discussion of the need for modernisation and adaptation to present economic conditions. An analysis of the socio-economic characteristics of the institutional environment is carried out and the directions for their formation up to a level corresponding to the development strategy of the territory, small town or municipality are determined. The indicators of the development of the institutional environment of small towns are characterised on the example of three subjects of the Russian Federation: Perm Krai, Tula and Vladimir oblast. Data on three types of institutions constitutional, economic and social - are considered together with living standards. The composition of the institutions of the business environment, education, culture and sport is analysed. The data on budget indicators of small towns of the federal subjects under consideration are reflected and problems concerning local budget deficits in the majority of municipalities are identified. Conclusion. Based on the identified directions and criteria for the development of the institutional environment, the directions for modelling the sustainable development of territories are developed.

Acknowledgment. The work was financially supported by the grant of the Russian Science Foundation (project No. 17-18-01324) "Sustainable development of the economy of territories based on the network interaction of small towns and regional centres".

Keywords: institutional environment, sustainable development, territory, modelling 
Введение. Развитие как ключевое понятие экономической науки наполняется ныне новым содержанием. Это связано, в первую очередь, с осознанием того факта, что социальные аспекты функционирования человеческого сообщества оказывают значительное влияние на развитие разноуровневых экономических систем - от малых предприятий до крупных территориальных образований. Именно поэтому концепция устойчивого развития территорий стала сегодня объектом пристального внимания практически во всех сферах человеческой жизнедеятельности. Переход к устойчивому развитию территорий должен основываться на принципах экономической эффективности, гармоничности развития человека и окружающей среды, социальной справедливости, инновационности и технологичности [7]. Отсюда можно сделать вывод, что на первый план в современном территориальном развитии выдвигается институциональная составляющая, которая включает в себя познание основополагающих для развития общества цивилизационных норм и ценностей.

Особенно актуальными эти проблемы являются для развивающихся территорий, переживающих фундаментальные трансформации институциональной структуры, которые охватывают все сферы их общественной жизнедеятельности и влияют на экономические и социальные преобразования. Их стратегической целью является развитие социально-ориентированной рыночной экономики и выход на траекторию устойчивого развития. Речь идет об управляемом социально-экономическое развитии, не нарушающем институциональной основы развития территории и направленном на обеспечение выживания и непрерывного прогресса общества в пределах данной территории. Для перехода на путь устойчивого развития важное значение имеют все составляющие институционной среды: экономические, политические, этические, культурные, экологические с учетом их институциональной основы.

Постановка задачи. Современное состояние экономики России и её регионов не в последнюю очередь обусловлено неэффективностью функционирования базовых экономических институтов. При этих обстоятельствах повышение институциональной эффективности для обеспечения устойчивого развития территориальных хозяйственных систем является не только актуальной теоретической проблемой, но и важной практической задачей. Следовательно, возникает потребность осмысления, оценивания и моделирования развития территорий в институциональном контексте.

Методы исследования. Диалектический метод познания экономических и социальных процессов заключается в исследовании отдельных показателей инфраструктуры и направлений моделирования устойчивого развития территорий, что позволяет сделать определенные выводы о наличии структурных проблем и тенденций, характерных для современного периода и предложить рекомендации с учетом специализации малых городов Тульской, Владимирской областей, Пермского края.

Метод системного анализа заключается в комплексном анализе социальноэкономической ситуации с учетом сложившейся специализации рассматриваемых территорий, а также особенностей институциональной среды, в совокупности позволяя сделать научно обоснованные выводы о качестве развития каждого аспекта рассматриваемой проблемы.

Формально-логический метод состоит в интерпретации фактов на основании различной информации статистического характера, которая позволяет обеспечить всесторонними данными об исследуемой проблеме.

Обсуждение результатов. Как отмечают Фролов Д.П. и Соловьева И.А., в основе институционального подхода к стратегическому планированию и управлению развитием территорий лежит задача минимизации издержек взаимодействий (то есть трансакционных издержек) хозяйствующих субъектов для реализации ими своих инициатив. Средствами снижения трансакционных издержек в территориальной экономике являются институты - формальные правила, неформальные нормы, органы, процедуры, обычаи, традиции, коллективные ментальные модели (убеждения, стереотипы и др.), регулирующие поведение различных групп хозяйствующих субъектов. Совокупность институтов территории или ее «институциональная структура является важнейшей частью региональной и местной стратегии экономического развития» [16, c.40]. 
Российский исследователь Беляев А.Е. рассматривает вопросы разработки стратегии устойчивого развития территории на основе моделирования условий и отмечает, что процессы воздействия институтов на развитие территорий, структура и иерархия институтов и их специфика имеют выраженный региональный характер, что обусловливает регионализм институтов устойчивого развития территорий [2]. Иерархия институтов, предложенная Беляевым А.Е., может быть использована для определения характеристик институциональной среды территориального развития.

Российский исследователь Нуртдинов А.Р. исследует вопросы определения концептуальных основ формирования институциональной среды как условия устойчивого экономического развития территорий [5]. Нуртдинов А.Р. на основе построенной модели выделяет в качестве главной причины неудач некоторых экономических реформ игнорирование российскими реформаторами достижений институциональной теории [5, с.189]. Кроме того, Нуртдиновым А.Р. дана авторская классификация социальных институтов, оказывающих воздействие на развитие территорий, рассматриваются механизмы воздействия социальных институтов на процесс устойчивого экономического развития, предлагаются конкретные возможности формирования институциональной среды территории в целях устойчивого развития.

Терешина М.В. отмечает роль институциональной теории в определении возможностей территориального развития [13]. Так как в последнее время имеет место растущая глобальная экономическая нестабильность, то роль условий достижения устойчивого экономического развития страны и ее отдельных территорий возрастает.

Барлыбаев У.А. также отмечает отсутствие необходимой институциональной среды, формирующей предпосылки для эффективного управления устойчивым развитием подсистем национальной экономики [1, с.61]. При этом в качестве объекта исследования выступают сельские территории. Несмотря на то, что исследователем построена экономико-математическая модель развития сельских территорий с использованием институционального подхода, всё же набор условий институциональной среды развития территорий представляется ограниченным, не рассматриваются инновационные и некоторые важные социальные институты.

Исследователь Иванченко М.П. определяет современные теоретические подходы к анализу предпосылок и последствий функционирования различных по содержательному наполнению и форме общественно-политических и экономических институтов, необходимых для развития отдельных территорий [3]. При этом для обеспечения оптимальности институциональной среды развития отстающих территории исследователь предлагает трансплантацию институтов. Трансплантацию институтов, по мнению Иванченко М.П., в определенной мере можно отождествить с заимствованием технологий [4, с.62]. В качестве примеров исследователем рассмотрены Ленинградская и Московская области - наиболее развитые регионы России, что отделяет их по условиям развития от других регионов России.

Некоторые российские исследователи уделяют внимание отдельным институтам или группам институтов, оказывающим влияние на развитие территорий и малых городов. Так, например, исследователь Приходченко О.С. рассматривает развитие территорий, прежде всего, с точки зрения различных государственных институтов, связанных с формирование бюджетных доходов и расходов [5, с.54]. Моделью, которую исследователь предлагает использовать для определения возможностей развития территорий, является программное бюджетирование и стратегирование. Данная модель является достаточно эффективным инструментом определения условий развития территории, хотя и ограничена узкой группой институтов.

Авторы Тамбовцев В. и Полтерович В. отмечают многообразие типов институтов, представленных в малых городах. Исследователи группируют институты по признаку целенаправленности и осознанности создания и выделяют спонтанно возникшие, заимствованные и спроектированные институты $[10,12]$. С точки зрения проектирования развития малых городов данная классификация имеет особое значение, так как позволяет разделить институты малых городов на те, которые можно искусственно инициировать, и те, что возникают самостоятельно или извне. Это важно при определении опорных социальных и экономических структур, кото- 
рые являются поддерживающими по отношению к общей стратегии развития территорий и малых городов.

В целях моделирования устойчивого развития малых городов необходимо также выделение институтов по таким признакам, как сложность изменения института, инертность, а также централизация института. Особое значение в рамках местного управления на уровне малых городов имеет классификация институтов по уровням регулирования - на федеральные, региональные и местные соответственно. Данные уровни закреплены в законодательстве страны, что является поддерживающим фактором для формирования и группировки институтов в малых городах именно по этому признаку. Как отмечает Тамбовцев В., институциональная среда малых городов формируется, прежде всего, на муниципальном уровне [12], но должна включать в себя институты других уровней в качестве поддержки и определения общей стратегии развития.

Исходя из рассмотренных научных исследований $[4,5,7-10,12]$, касающихся вопросов формирования институциональной среды развития территорий, можно выделить следующие группы институтов малых городов:

1. Надконституционные (поведенческие) институты - сюда относятся устоявшиеся локальные традиции и обычаи малого города, например, особые местные праздники, почитание покровителя города и др. В современных условиях, казалось бы, данная группа институтов должна постепенно терять свою значимость, но, учитывая старение населения малых городов [16], группа поведенческих институтов имеет весьма крепкие позиции в современных малых городах.

2. Конституционные (политические) институты, куда относятся правила избрания и назначения представителей органов местного и общественного самоуправления. Основой для данных институтов являются такие нормативные акты, как Положение об администрации муниципального образования и Положение о территориальном общественном самоуправлении.

3. Экономические институты - наиболее многочисленная группа институтов малых городов. Сюда можно отнести:

- институты, регулирующие предпринимательскую деятельность и формирующие инвестиционный климат,

- институты развития социальной сферы малого города (например, образование, здравоохранение, культура, спорт),

- институты системы финансов малого города,

- институты, обеспечивающие развитие городской инфраструктуры,

- институты, формирующие условия для повышения туристической привлекательной и развития туризма малого города.

Данная группа институтов является определяющей для формирования устойчивого развития малых городов, так как институты данной группы позволяют обеспечить высокие показатели уровня жизни населения малых городов, что является основной целью устойчивого развития территории.

Стратегии развития малых городов и регионов, базирующиеся на институциональном подходе, направлены, с одной стороны, на выявление и преодоление институциональных ограничений (в том числе административных барьеров, неэффективных процедур и механизмов регулирования и др.) в использовании ресурсов территории, а с другой - на формирование качественной институциональной среды для разных групп стейкхолдеров [16, с.34-35].

В качестве методологической основы для таких индикаторов могут быть использованы показатели рейтинга «Ведение бизнеса» (Doing Business), отражающие степень удовлетворенности предпринимателей сроками получения разрешений на строительство, подключения к электроснабжению, регистрации бизнеса и собственности и т.д., а также индикаторы индекса «Валового национального счастья» (Gross National Happiness Index), включающие показатели психологического благополучия, здоровья, культурного разнообразия, стандартов жизни, удовлетворенности качеством государственного управления, использования времени и др. [4]. 
Далее рассмотрены некоторые показатели, характеризующие уровень развития институциональной среды в малых городах субъектов РФ: Пермском крае, Владимирской и Тульской областях - табл. 1. Методика обобщения показателей для характеристики институциональной среды представлена органами статистики.

Таблица 1. Показатели развития институциональной среды малых городов на примере субъектов РФ [27]

Table 1. Indicators of development of institutional environment of small towns on the example of subjects of the Russian Federation

\begin{tabular}{|c|c|c|c|}
\hline \multirow[b]{2}{*}{ Показатель } & \multicolumn{3}{|c|}{ Субъекты } \\
\hline & $\begin{array}{l}\text { Пермский } \\
\text { край }\end{array}$ & $\begin{array}{c}\text { Владимирская } \\
\text { область }\end{array}$ & $\begin{array}{c}\text { Тульская } \\
\text { область }\end{array}$ \\
\hline \multicolumn{4}{|c|}{ Конституционные институты } \\
\hline $\begin{array}{c}\text { Наличие муниципальных } \\
\text { образований, единиц }\end{array}$ & 29 & 80 & 23 \\
\hline $\begin{array}{l}\text { Число муниципальных образований, } \\
\text { участвующих на добровольной основе } \\
\text { в объединениях муниципальных обра- } \\
\text { зований, в межмуниципальных не- } \\
\text { коммерческих организациях, единиц }\end{array}$ & 27 & 80 & 22 \\
\hline \multicolumn{4}{|c|}{ Экономические институты } \\
\hline $\begin{array}{c}\text { Муниципальные унитарные } \\
\text { предприятия, единиц }\end{array}$ & 51 & 10 & 12 \\
\hline $\begin{array}{l}\text { Банки и иные финансовые организа- } \\
\text { ции или их филиалы и представитель- } \\
\text { ства, единиц }\end{array}$ & 2 & 4 & 3 \\
\hline $\begin{array}{l}\text { Число субъектов малого и среднего } \\
\text { бизнеса }\end{array}$ & 3124 & 6309 & 3469 \\
\hline \multicolumn{4}{|c|}{ Социальные и институты уровня жизни } \\
\hline $\begin{array}{l}\text { Образовательные организации, еди- } \\
\text { ниц }\end{array}$ & 19 & 84 & 32 \\
\hline Организации культуры, единиц & 57 & 86 & 6 \\
\hline Организации спорта, единиц & 25 & 2 & 8 \\
\hline \multicolumn{4}{|l|}{$\begin{array}{c}\text { Местный бюджет на текущий год, } \\
\text { (тыс.руб) }\end{array}$} \\
\hline доходы & 2203626 & 1628062 & 3148183 \\
\hline расходы & 2278613 & 1597459 & 3507493 \\
\hline дефицит (-), профицит (+) & -74987 & +30603 & -359310 \\
\hline
\end{tabular}

Исходя из данных табл. 1, можно особо выделить развитие экономических институтов в малых городах Владимирской области - данный регион лидирует по числу банковских организаций и субъектов малого и среднего бизнеса (табл. 1. и рис. 1). Также развитым в части экономических характеристик институциональной среды является, согласно данным табл. 1, Тульская область.

Отразим данные о численности субъектов малого и среднего бизнеса в малых городах Пермского края, Владимирской и Тульской областей на рис.1: 


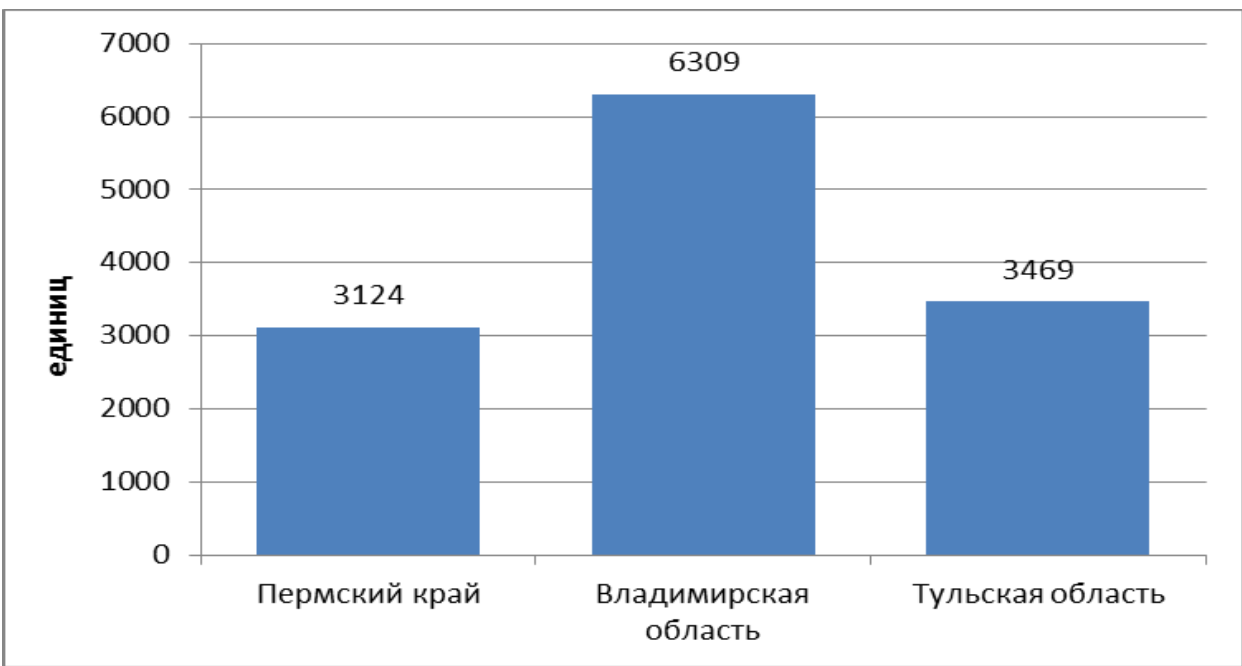

Рис. 1. Численность субъектов малого и среднего бизнеса в малых городах

Пермского края, Владимирской и Тульской областей на 2016 год [27]

Fig. 1. The number of subjects of small and medium-sized businesses in small towns of the Perm territory, the Vladimir and Tula regions for the year 2016

На рис. 2 представлены показатели, характеризующие социальные институты в малых городах рассматриваемых регионов:

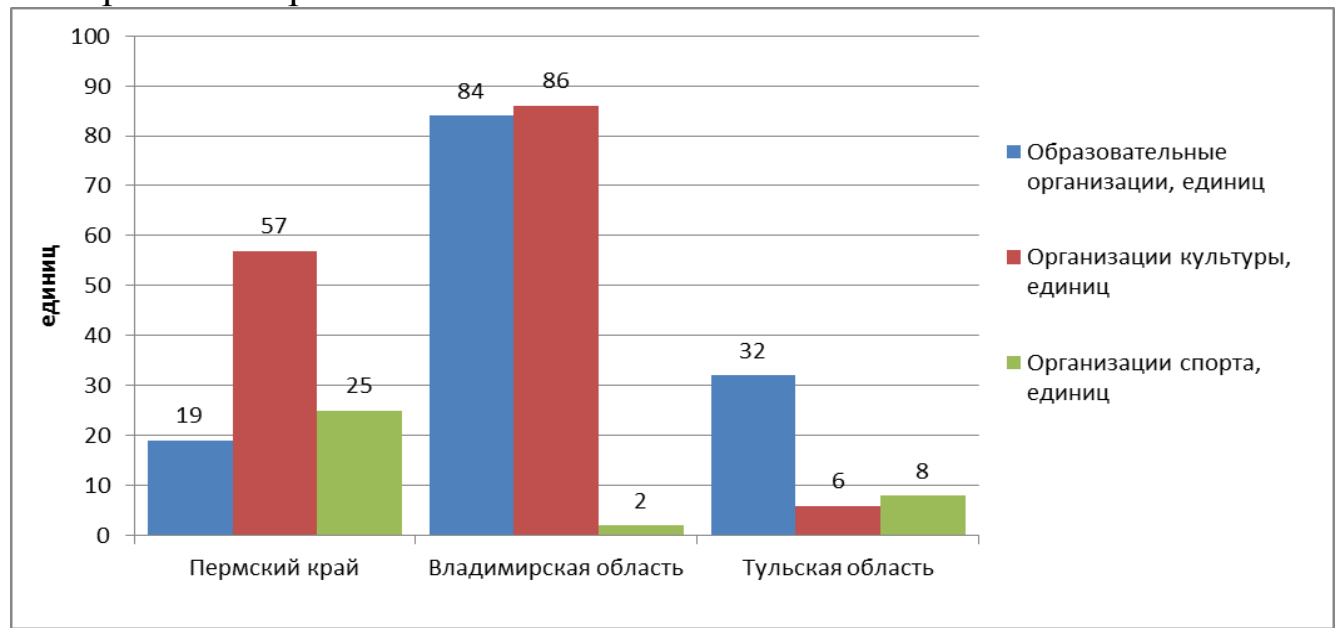

Рис. 2. Показатели, характеризующие социальные институты в малых городах

Пермского края, Владимирской и Тульской областей [27]

Fig. 2. The indicators characterizing social institutions in small towns of the Perm territory, the Vladimir and Tula regions

Как можно видеть по данным рис.2., по социальным характеристикам институциональной среды среди рассмотренных регионов лидирует Владимирская область - по числу образовательных, культурных и спортивных организаций малые города данного региона опережают малые города других рассмотренных областей.

Таким образом, можно говорить о наиболее развитых социальных институтах именно в малых городах Владимирской области.

На рис. 3 отражены показатели бюджетных доходов и расходов по малым городам Пермского края, а также Владимирской и Тульской областей.

Во всех регионах, кроме Владимирской области, малые города испытывают дефицит бюджета. Наибольший дефицит имеет место в малых городах Тульской области, профицит имеет место в малых городах Владимирской области, что свидетельствует о лучшем обеспечении бюджетных функций в малых городах данного региона, что позволяет говорить о более высоком уровне жизни населения малых городов Владимирской области.

В целом, исходя из рассмотренных показателей, можно говорить о приемлемом развитии институциональной среды в малых городах Владимирской области (в части экономических и социальных институтов), а также Пермского края (в части экономических институтов), но 
необходимо отметить, что данная методика является не совсем точной и не позволяет полноценно осветить развитие институциональной среды малых городов.

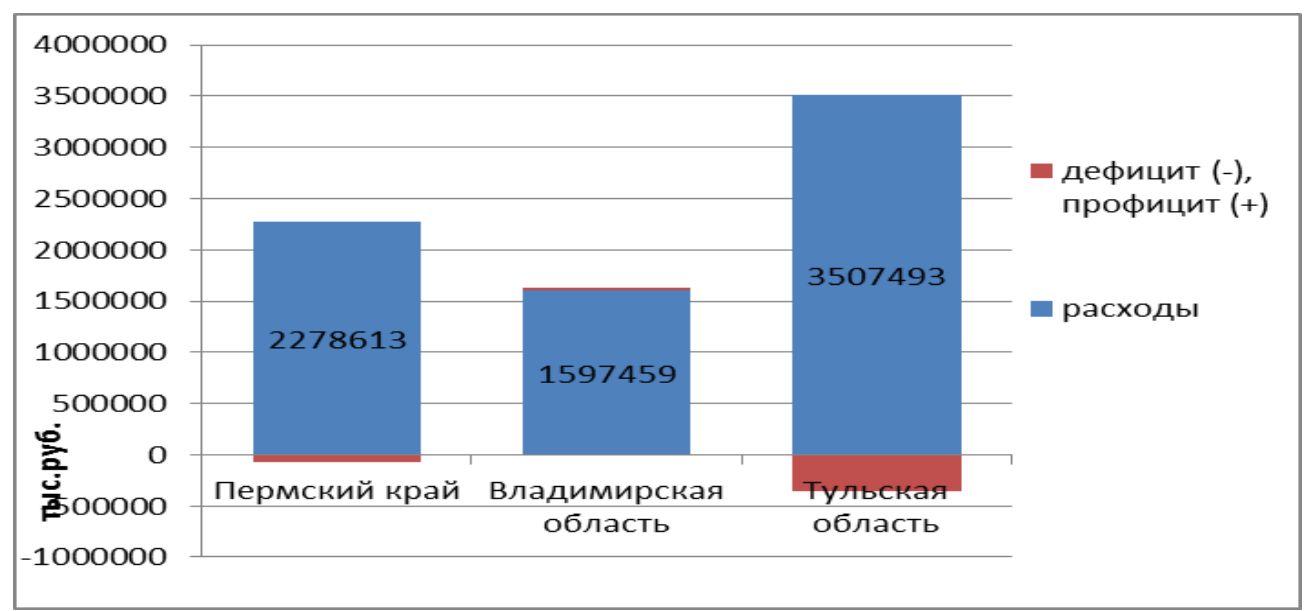

Рис. 3. Показатели бюджетных доходов и расходов по малым городам

Пермского края, Владимирской и Тульской областей [27]

Fig. 3. Indicators of budget revenues and expenditures in small towns of the Perm territory, the Vladimir and Tula regions

Важные условия формирования институциональной среды территориального развития определены в работах Усковой Т.В., в которых предлагаются инструменты оценки влияния экономических факторов на развитие территорий [14-15].

Различным аспектам устойчивого развития посвящено много работ зарубежных исследователей. Понятийный аппарат, методология и механизмы формирования среды территориального развития сформулированы в документах $\mathrm{OOH}$ «Наше общее будущее», «Повестка дня на XXI век» [26], Декларация Рио и др. Особое место в работах зарубежных исследователей уделяется характеристике рациональных институциональных условий производства и потребления для развития территорий. Модели развития территорий зачастую строятся на основе оптимизации потребностей, и, в соответствии с этим, трансформации производственных и экономических характеристик институциональной среды $[19,20]$.

Возможность моделирования развития территорий с позиции институционального подхода обоснована в трудах зарубежных исследователей [17-19, 21].

Так, Й. Эдда сформировал перечень факторов, оказывающих влияние на развитие территорий и также предложил математическую имитационную модель, позволяющую выявить влияние факторов институциональной среды на развитие территории [19].

Исследование, проведенное зарубежными исследователями Хайнесом Эйджем и Джоном Харрисоном, основывается на аспектах новейшего институционального анализа [18], который ведет к формулированию возможности моделирования развития территорий исходя из текущего состояния институтов, воздействующих на данную территорию. Ученые построили EPR-модель, которая позволяет увидеть конкретные причинно-функциональные связи (в том числе - институционального характера), существующие в системе развития территории. Внимание вопросам определения характеристик институциональной среды территориального развития уделяется и исследователями из стран СНГ [22 -25]. Наибольший упор в указанных работах делается на вопросах социально-экономического развития институтов, оказывающих влияние на территориальное развитие, что несколько сужает понимание институциональной концепции устойчивого развития.

Для понимания механизмов реализации модели устойчивого развития необходимо уделить больше внимания анализу влияния модели устойчивого развития в системе политических, общественных и других институтов.

Рассмотрим направления моделирования устойчивого развития территорий на основе институциональной среды на примере малых городов Пермского края, с преобладающей промышленной специализацией (табл. 2). 
Таблица 2. Характеристика малых городов Пермского края по экономической специализации [27]

Table 2. Feature of small towns in Perm Krai on economic specialization

\begin{tabular}{|c|c|c|}
\hline $\begin{array}{l}\text { Малые } \\
\text { города }\end{array}$ & Отрасль специализации & $\begin{array}{c}\text { Направления диверсификации } \\
\text { экономики }\end{array}$ \\
\hline Чермоз & $\begin{array}{l}\text { Сельское хозяйство, розничная торговля, маши- } \\
\text { ностроение («ООО Синергия») }\end{array}$ & $\begin{array}{l}\text { Развитие познавательного, экологиче- } \\
\text { ского, агротуризма }\end{array}$ \\
\hline Чердынь & $\begin{array}{l}\text { Разработка солевых месторождений, производ- } \\
\text { ство за чертой города }\end{array}$ & $\begin{array}{l}\text { Развитие религиозного, познаватель- } \\
\text { ного, экологического и агротуризма }\end{array}$ \\
\hline Усолье & $\begin{array}{l}\text { Сельское хозяйство, розничная торговля, лесная и } \\
\text { деревообрабатывающая промышленности }\end{array}$ & $\begin{array}{l}\text { Развитие религиозного и познаватель- } \\
\text { ного туризма }\end{array}$ \\
\hline Оханск & $\begin{array}{l}\text { Сельское хозяйство, производство пиломатериа- } \\
\text { лов, швейное производство (ОАО Оханская } \\
\text { швейная фабрика) }\end{array}$ & $\begin{array}{l}\text { Развитие экологического и агротуриз- } \\
\text { ма }\end{array}$ \\
\hline Гремячинск & $\begin{array}{l}\text { Лесопереработка (ДОК Гремячинский, ООО } \\
\text { «ППК»), газокомпрессорная станция (Гремя- } \\
\text { чинское ЛПУ МГ), автомобилестроение (завод } \\
\text { ОАО «Автоспецоборудование»), легкая промыш- } \\
\text { ленность }\end{array}$ & $\begin{array}{l}\text { Образование, здравоохранение и эко- } \\
\text { логический туризм }\end{array}$ \\
\hline Горнозаводск & Монопроизводство ОАО «Горнозаводскцемент» & $\begin{array}{l}\text { Транспортная отрасль, сфера культу- } \\
\text { ры }\end{array}$ \\
\hline Александровск & $\begin{array}{l}\text { Развитие промышленного производства (ОАО } \\
\text { «Александровский машиностроительный завод», } \\
\text { ОАО «Алекстром» }\end{array}$ & $\begin{array}{l}\text { Образование, здравоохранение, } \\
\text { транспортная отрасль и туризм }\end{array}$ \\
\hline Очер & $\begin{array}{l}\text { Литейная, мебельная промышленность, производ- } \\
\text { ство пиломатериалов, сельское хозяйство, маши- } \\
\text { ностроение (ОАО «Очёрский машиностроитель- } \\
\text { ный завод») }\end{array}$ & $\begin{array}{l}\text { Туризм и рекреация, экологический и } \\
\text { агротуризм }\end{array}$ \\
\hline Красновишерск & $\begin{array}{l}\text { Лесная, деревообрабатывающая промышлен- } \\
\text { ность, цветная металлургия. Крупные предприя- } \\
\text { тия являются банкротами }\end{array}$ & $\begin{array}{l}\text { Образование, здравоохранение, } \\
\text { транспортная отрасль, экологический } \\
\text { туризм }\end{array}$ \\
\hline Кизел & $\begin{array}{l}\text { Ликвидация основных градообразующих пред- } \\
\text { приятий, бюджетная сфера }\end{array}$ & $\begin{array}{l}\text { Туризм и рекреация, экологический и } \\
\text { агротуризм }\end{array}$ \\
\hline Нытва & $\begin{array}{l}\text { Градообразующее предприятие - ОАО Нытвен- } \\
\text { ский металлургический завод }\end{array}$ & $\begin{array}{l}\text { Развитие познавательного, экологиче- } \\
\text { ского и агротуризма }\end{array}$ \\
\hline Губаха & $\begin{array}{lcc}\text { Химическая } & \text { промышленность } & \text { ПАО } \\
\text { «Метафракс», ОАО «Губахинский кокс» } & \end{array}$ & Транспорт, сфера культуры и туризм \\
\hline Oca & $\begin{array}{l}\text { Машиностроение, деревообработка, пищевая } \\
\text { промышленность }\end{array}$ & $\begin{array}{l}\text { Культурный центр - развитие позна- } \\
\text { вательного туризма }\end{array}$ \\
\hline Верещагино & $\begin{array}{l}\text { Машиностроение, сельское хозяйство, текстиль- } \\
\text { ная промышленность }\end{array}$ & Транспорт, промышленность и туризм \\
\hline Кудымкар & $\begin{array}{l}\text { Пищевая промышленность (ОАО «Молоко», ОАО } \\
\text { «Мясокомбинат»), торговля }\end{array}$ & $\begin{array}{l}\text { Развитие религиозного, познаватель- } \\
\text { ного, экологического и агротуризма }\end{array}$ \\
\hline Чернушка & $\begin{array}{l}\text { Нефтяная промышленность и строительство } \\
\text { (ООО «Лукойл - Пермь»); ремонтное производ- } \\
\text { ство (ООО «АРГОС»-ЧУРС); строительство до- } \\
\text { рог (ООО «ДОРОС»), выпуск кирпича (ООО } \\
\text { «Чернушкастройкерамика») }\end{array}$ & $\begin{array}{l}\text { Промышленность, транспорт, туризм, } \\
\text { санаторно-курортная деятельность }\end{array}$ \\
\hline Добрянка & $\begin{array}{l}\text { Топливно-энергетический и лесопромышленный } \\
\text { комплекс (филиал «Пермская ГРЭС» АО «Интер } \\
\text { РАО- Электрогенерация»; НГДУ «Полазнанефть» } \\
\text { ЗАО «Лукойл-Пермь», ЗАО «Лукойл - Бурение - } \\
\text { Пермь», АО «Добрянка-мебель», филиал ЗАО ПО } \\
\text { «Уралэнергомонтаж») }\end{array}$ & $\begin{array}{l}\text { Промышленность, транспорт, туризм, } \\
\text { санаторно-курортная деятельность }\end{array}$ \\
\hline Чусовой & $\begin{array}{l}\text { Черная металлургия, машиностроение и металло- } \\
\text { обработка (ОАО «Чусовский металлургический } \\
\text { завод», «УралДомнаРемонт», «Металлург Сер- } \\
\text { вис»). }\end{array}$ & $\begin{array}{l}\text { Промышленность, транспорт, } \\
\text { туризм, санаторно-курортная } \\
\text { деятельность }\end{array}$ \\
\hline
\end{tabular}


Ряд моногородов испытывает экономические проблемы, связанные с упадком или банкротством промышленных предприятий [6].

Представим схематично промышленную институциональную среду Пермского края (рис. 4).

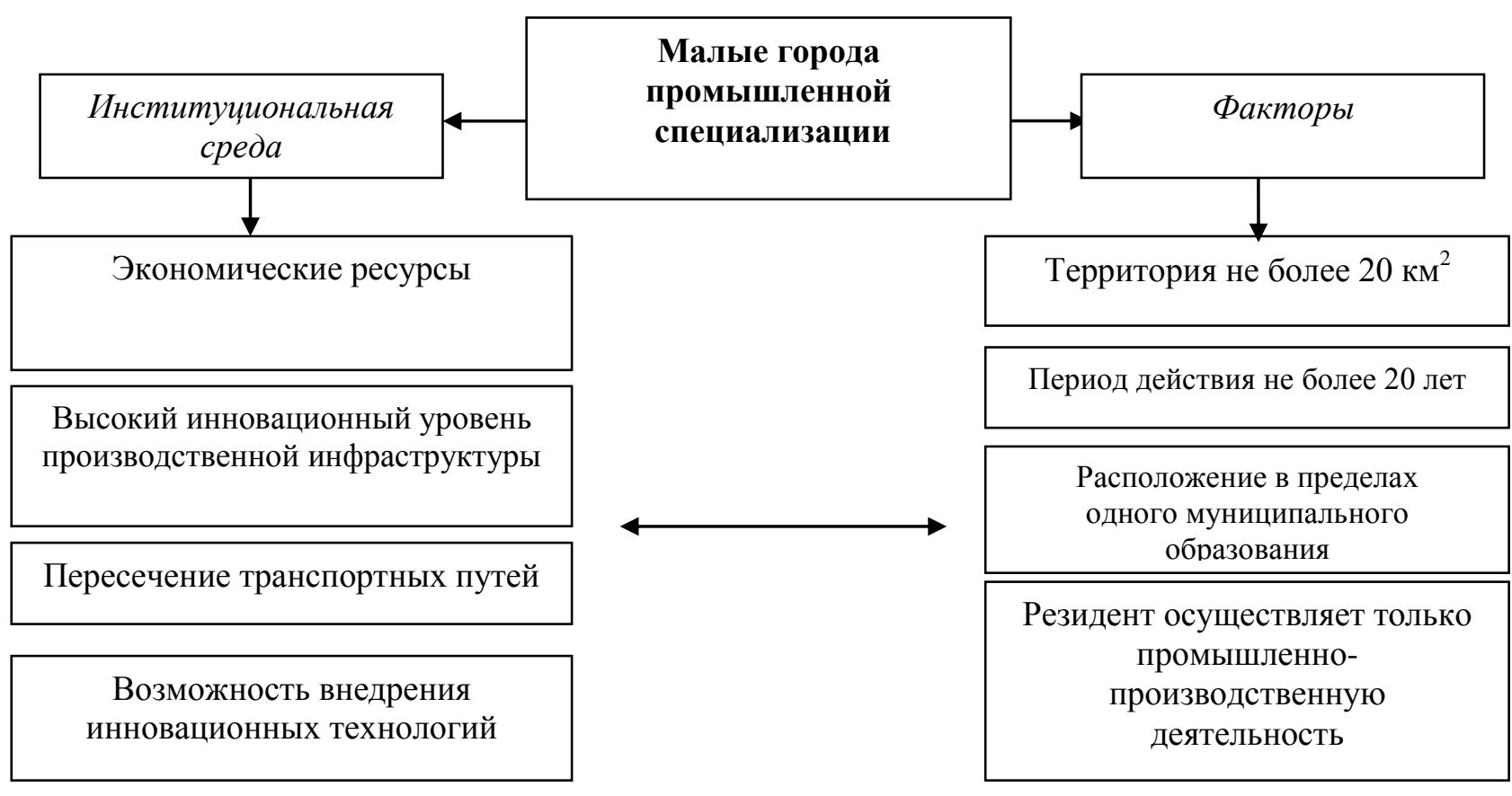

Научно-технические ресурсы

\section{Рис. 4. Основные характеристики институциональной среды малых городов Пермского края с промышленной специализацией [7]}

Fig. 4. The main characteristics of the institutional environment of small towns of the Perm region with industrial specialization

Можно видеть сочетание нескольких характеристик институциональной среды, к которым относится научно-технический потенциал и инновации. Охарактеризуем динамику инноваций на примере рассматриваемых субъектов РФ (рис.5).

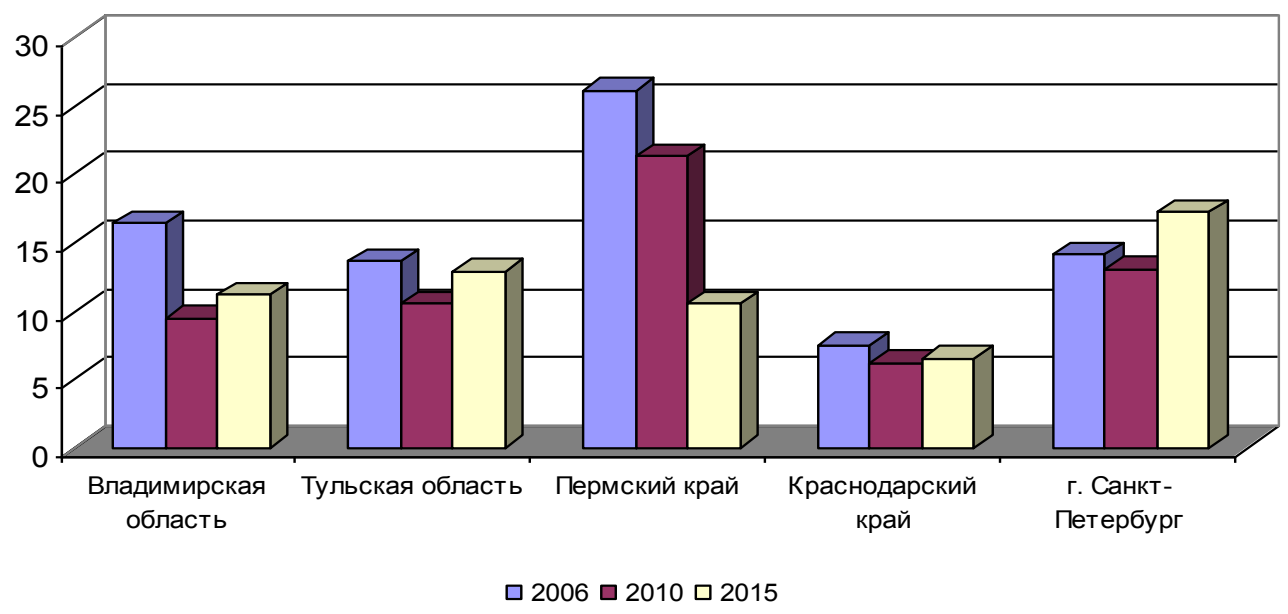

Рис. 5. Удельный вес организаций, осуществляющих технологические, маркетинговые, организационные инновации, \% [8]

Fig. 5. The share of organizations implementing technological, marketing, organizational innovation, $\%$ 
Пермский край являлся лидером в 2006 году - 26,1\% организаций осуществляли инновационную деятельность; в 2015 году на первое место вышел г. Санкт-Петербург - 17,2\%, он же является единственным из рассматриваемой группы субъектов, показавший пророст инновационной деятельности. Необходимо рассмотреть в процентном соотношении от общего объема отгруженных товаров, работ, услуг (рис. 6).

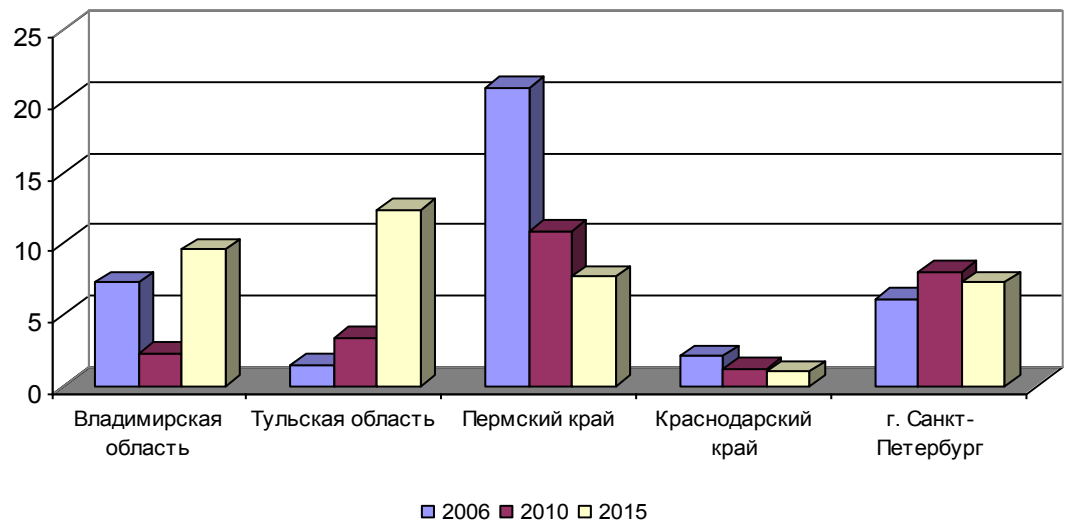

Рис. 6. Доля инновационных продуктов, работ, услуг в общем объеме, \% [8]

Fig. 6. The share of innovative products, works, services in total amount, \%

Отметим, что в регионах развиваются две тенденции: рост инновационных продуктов, работ, услуг в общей доле: Владимирская, Тульская области; снижение: Пермский, Краснодарский края, г. Санкт-Петербург (при росте количества предприятий, занятых инновациями). Особенно резким является сокращение по Пермскому краю - с 20,9\% до 7,7\%.

Вывод. Институциональная среда оказывает качественное влияние на социальноэкономическое пространство территорий, обеспечивает устойчивое развитие.

Аналитическое обощение результатов исследования выявило, что проблема институтов является актуальной в современной экономической региональной политике, так как ее решение способствует выходу территории, малого города, муниципального образования на новый уровень специализации.

Анализ институциональной среды промышленности был проведен на примере Пермского края в сравнении с некоторыми регионами, обладающими сопоставимой специализацией. Было выявлена тенденция к сокращению инновационной и инвестиционной активности, обусловленной частичным спадом промышленного производства, замедлением темпов формирования индустриальных парков, целью создания которых была оптимизация существующего производства, рациональное использование промышленных площадей (производственной инфраструктуры).

Установлено, что промышленные города развиваются за счет промышленного потенциала территории за счет использования имеющихся природных ресурсов (месторождения руд), большого количества рабочей силы и высококвалифицированного персонала, а также привлечения отечественного и иностранного капитала.

Формирование и развитие промышленности и технопарков на территории Пермского края основывается на следующих требованиях:

- повышение инвестиционной привлекательности и конкуренции российской экономики;

- повышение конкурентоспособности российских предприятий и их готовность к внедрению инноваций;

- создание условий для экспорта товаров и повышения конкурентоспособности на рынке товаров и услуг;

- развитие и применением новых технологий управления персоналом.

Можно сделать вывод, что обладая достаточно развитой промышленной инфраструктурой, Пермский край демонстрирует спад основных показателей промышленности, способствующих модернизации и устойчивому росту. В связи с этим необходимо отметить следующие особенности: на деятельность институциональной среды оказывают влияние макроэкономиче- 
ские факторы, в первую очередь, сокращение денежной массы; негативные ожидания привели к сокращению вложений в длительные проекты, характерные для промышленности (ввод новых мощностей, модернизация основных фондов).

Характеристики институциональной среды для обеспечения устойчивого роста территорий: низкая доля износа объектов материального производства; удовлетворение основных потребностей населения территории; наличие инвестиционно-инновационных предприятий, относящихся к государству и бизнес-среде.

Моделирование устойчивого развития промышленных территорий включает основные направления: транспортно-логистические сети; усиление сложившейся специализации; диверсификация экономики на основе перспективных направлений специализации; включение потенциальных возможностей в проекты новых продуктов и услуг, обладающих спросом; обеспечение устойчивых взаимосвязей инфраструктуры различных типов на основе выявленных факторов взаимовлияния, обеспечивающих синергетический эффект.

\section{Библиографический список:}

1. Барлыбаев У.Д. Институциональные аспекты устойчивого развития сельских территорий в условиях становления. Москва, 2015. -333 с.

2. Беляев А.Е. Актуальные проблемы устойчивого развития территории // Kant. - 2015. №2 (5). - c.19-21.

3. Иванченко М.П. Роль государства в формировании благоприятной институциональной среды, обеспечивающей развитие региона (на примере Ленинградской области) // Проблемы управления. - 2015. №15. - с.26-31.

4. Иванченко М.П. Формирование институтов роста развитой территории на примере Ленинградской области) // Проблемы управления. - 2014. №20. - с.61-64.

5. Нуртдинов А. Р. Институциональная среда как условие устойчивого экономического развития // Вестник Казанского технологического университета. - 2016. №6. - с.186-193.

6. Оборин М.С., Пахалов А.М., Шерешева М.Ю. Эффективность стратегического планирования развития малых городов на основе сетевого механизма координации // Вестник Московского университета. Серия 6: Экономика. № 4, 2017. - С. 100-117.

7. Оборин М.С., Шерешева М.Ю., Пахалов А.М. Институциональная среда как фактор формирования инвестиционного климата малых городов России // Ars Administrandi (Искусство управления). Том 9, № 3, 2017. - С. $370-394$

8. Оборин М.С., Шерешева М.Ю., Иванов Н.А. Обоснование стратегических ориентиров социальноэкономического развития малых городов России // Вестник Пермского университета. Сер. «Экономика» $=$ Perm University Herald. Economy. Том 12. № 3, 2017. - C. 437-452.

9. Пахалов А.М. Институциональное проектирование как инструмент улучшения инвестиционного климата // Российское предпринимательство. 2016. Т. 17, № 18.С. 2335-2350.

10. Полтерович В.М. Трансплантация экономических институтов // Экономическая наука современной России. 2001. № 3. С. 25-50.

11. Приходченко О.С. Формирование бюджетной стратегии на региональном уровне // Известия ЮгоЗападного государственного университета. Серия Экономика. Социология. Менеджмент. 2014. № 1. С. 53-56.

12. Тамбовцев В.Л. Защита прав собственности и инвестиционный климат России // Журнал НЭА. 2012. № 1 (13). C. 163-165.

13. Терешина М.В., Формирование механизма устойчивого развития региона: экономические и институциональные условия, диссертация и автореферат на соискание степени доктора экономических наук ВАК 08.00.05. - Москва. 2014. - 333 с.

14. Ускова Т.В. Социально-экономическое развитие территорий: проблемы эффективности региональной политики //Проблемы развития территории. - 2016. - №. 2. - С. 7-18.

15. Ускова Т.В., Ворошилов Н.В., Гутникова Е.А., Кожевников С.А., Социально-экономические проблемы локальных территорий: монография /. - Вологда: ИСЭРТ РАН, 2013. - 196 с.

16. Фролов Д.П., Соловьева И.А. Будущее стратегий территориального развития: анализ современных методологий // Региональная экономика: теория и практика. 2016. № 10 (433). С. 28-45.

17. Bishop, Michael. New State Spaces and Contested Territories: A Critical Analysis of Joint Regional Planning Panels. URBAN POLICY AND RESEARCH Volume: 32 Issue: 2 Pages: 185-201 Published: 2014.

18. Harrison John; Age S. When regions collide: in what sense a new 'regional problem'? Environment and planning A Volume: 46 Issue: 10. P. 2332-2352. Published: 2014.

19. Johannesen Edda; Hoines, Dolgov, Andrey V.; et al. Demersal Fish Assemblages and Spatial Diversity Patterns in the Arctic-Atlantic Transition Zone in the Barents Sea. PLOS ONE Volume: 7 Issue: 4. Article Number: e34924 Published: APR 17. 2012.

20. Granger, Alan Purvis, Martin, Learning for sustainable development: geographical perspectives - Earthscan, $2013-416 \mathrm{p}$ 
21. Zimmerbauer, Kaj. Constructing peripheral crossborder regions in planning: territory-network interplay in the Barents region.environment and planning A Volume: 46 Issue: 11 Pages: 2718-2734 Published: 2014.

22. Білорус О.Г. Імперативи сталого розвитку в епоху глобалізації // Збірник наукових праць Вінницького національного аграрного університету. Серія: економічнінауки. - 2014. Т. 1. № 1. - с. 16-27.

23. БуркинськийБ.В. "Зелена" економікакрізьпризмутрансформаційнихзрушеньвУкраїн. - Одеса: ІПРЕЕДНАНУкраїни - Саки: ПП "ПідприємствоФєнікс", 2015. - 348 с.

24. ІвановаТ. Л. Глобальніімакроекономічнііндикатористалогорозвиткунаціональноїекономіки // Інноваційнаекономіка. - 2015. № 10 (48). - с. 86-93.

25. Солошич I.О. "Зелена економіка" в контексті забезпечення переходу України до сталого розвитку // Економічний форум. - 2016. № 28. - с. 30-36.

26. Повестка дня на XXI век. Принята Конференцией ООН по окружающей среде и развитию, Рио-деЖанейро, 3-14 июня 1992 года. [Электронный ресурс]. - Режим доступа: http://www.un.org/ru/documents/ decl_conv/conventions/pdf/agenda21.pdf (29.10.2017).

27. Официальный сайт Федеральной службы статистики [Электронный ресурс]. - Режим доступа: http://www.gks.ru/ (29.10.2017).

\section{References:}

1. Barlybaev U.D. Barlybaev U.D. Institutsional'nye aspekty ustoichivogo razvitiya sel'skikh territorii v usloviyakh stanovleniya. Moskva; 2015. 333 s. [Barlybaev U.D. Institutional aspects of sustainable development of rural areas in the conditions of formation. Moscow; 2015. 333 p. (In Russ.)]

2. Belyaev A.E. Aktual'nye problemy ustoichivogo razvitiya territorii. Kant. 2015;2 (5):19-21. [Belyaev A.E. Relevant issues of sustainable development of the territory. Kant. 2015;2 (5):19-21. (In Russ.)]

3. Ivanchenko M.P. Rol' gosudarstva v formirovanii blagopriyatnoi institutsional'noi sredy, obespechivayushchei razvitie regiona (na primere Leningradskoi oblasti). Problemy upravleniya. 2015;15:26-31. [Ivanchenko M.P. The role of the state in the formation of a favorable institutional environment proviging the development of the region (by the example of the Leningrad Oblast).Control Sciences. 2015;15:26-31. (In Russ.)]

4. Ivanchenko M.P. Formirovanie institutov rosta razvitoi territorii na primere Leningradskoi oblasti). Problemy upravleniya. 2014;20:61-64. [Ivanchenko M.P. Formirovanie institutov rosta razvitoi territorii na primere Leningradskoi oblasti). Control Sciences. 2014;20:61-64. (In Russ.)]

5. Nurtdinov A. R. Institutsional'naya sreda kak uslovie ustoichivogo ekonomicheskogo razvitiya. Vestnik Kazanskogo tekhnologicheskogo universiteta. 2016;6:186-193. [Nurtdinov A. R. Institutional environment as a condition of sustainable economic development. Vestnik Kazanskogo tekhnologicheskogo universiteta. 2016;6:186-193. (In Russ.)]

6. Oborin M.S., Pakhalov A.M., Sheresheva M.Yu. Effektivnost' strategicheskogo planirovaniya razvitiya malykh gorodov na osnove setevogo mekhanizma koordinatsii. Vestnik Moskovskogo universiteta. Seriya 6: Ekonomika. 2017;4:100-117. [Oborin M.S., Pakhalov A.M., Sheresheva M.Yu. Effectiveness of strategic planning for the development of small towns on the basis of a network coordination mechanism.Moscow University Economics Bulletin. Series 6:Economics. 2017;4:100-117. (In Russ.)]

7. Oborin M.S., Sheresheva M.Yu., Pakhalov A.M. Institutsional'naya sreda kak faktor formirovaniya investitsionnogo klimata malykh gorodov Rossii. Ars Administrandi (Iskusstvo upravleniya). 2017;9(3):370-394. [Oborin M.S., Sheresheva M.Yu., Pakhalov A.M. Institutional environment as a factor of investment climate formation in small Russian cities. Ars Administrandi (The Art of Management). 2017;9(3):370-394. (In Russ.)]

8. Oborin M.S., Sheresheva M.Yu., Ivanov N.A. Obosnovanie strategicheskikh orientirov sotsial'noekonomicheskogo razvitiya malykh gorodov Rossii. Vestnik Permskogo universiteta. Ser. "Ekonomika". 2017;12(3):437452. [Oborin M.S., Sheresheva M.Yu., Ivanov N.A. Substantiation of strategic landmarks of social and economic development of small cities of Russia. Perm University Herald. Economy. 2017;12(3):437-452. (In Russ.)]

9. Pakhalov A.M. Institutsional'noe proektirovanie kak instrument uluchsheniya investitsionnogo klimata. Rossiiskoe predprinimatel'stvo. 2016;17(18):2335-2350. [PakhalovA.M. Institutional design as a tool for improving the investment climate.Russian Journal of Entrepreneurship. 2016;17(18):2335-2350. (In Russ.)]

10. Polterovich V.M. Transplantatsiya ekonomicheskikh institutov. Ekonomicheskaya nauka sovremennoi Rossii. 2001;3:25-50. [Polterovich V.M. Transplantation of economic institutions. Economics of Contemporary Russia. 2001;3:25-50. (In Russ.)]

11. Prikhodchenko O.S. Formirovanie byudzhetnoi strategii na regional'nom urovne. Izvestiya Yugo-Zapadnogo gosudarstvennogo universiteta. Seriya Ekonomika. Sotsiologiya. Menedzhment. 2014;1:53-56. [Prikhodchenko O.S. Formation of the budget strategy at the regional level. Proceedings of South-West State University. Series Economy. Sociology. Management. 2014;1:53-56. (in Russ.)]

12. Tambovtsev V.L. Zashchita prav sobstvennosti i investitsionnyi klimat Rossii. Zhurnal NEA. 2012;1(13):163165. [Tambovtsev V.L. Protection of property rights and the investment climate in Russia. The Journal of the New Economic Association. 2012;1(13):163-165. (In Russ.)]

13. Tereshina M.V. Formirovanie mekhanizma ustoichivogo razvitiya regiona: ekonomicheskie i institutsional'nye usloviya. Dissertatsiya i avtoreferat na soiskanie stepeni doktora ekonomicheskikh nauk VAK 08.00.05. Moskva; 2014. 333 s. [Tereshina M.V. Formation of the mechanism of sustainable development of the region: economic and institutional conditions. Published summary and Doctor of Economy thesis VAK 08.00.05. Moscow; 2014. 333 p. (In Russ.)] 
14. Uskova T.V. Sotsial'no-ekonomicheskoe razvitie territorii: problemy effektivnosti regional'noi politiki. Problemy razvitiya territorii. 2016;2:7-18. [Uskova T.V. Socio-economic development of territories: problems of the effectiveness of regional policy. Problems of Territory's Development. 2016;2:7-18. (In Russ.)]

15. Uskova T.V., Voroshilov N.V., Gutnikova E.A., Kozhevnikov S.A. Sotsial'no-ekonomicheskie problemy lokal'nykh territorii: monografiya. Vologda: ISERT RAN; 2013. 196 s. [Uskova T.V., Voroshilov N.V., Gutnikova E.A., Kozhevnikov S.A. Socio-economic problems of local territories: a monograph. Vologda: ISERT RAN; 2013. 196 p. (In Russ.)]

16. Frolov D.P., Solov'eva I.A. Budushchee strategii territorial'nogo razvitiya: analiz sovremennykh metodologii. Regional'naya ekonomika: teoriya i praktika. 2016;10(433):28-45. [Frolov D.P., Solov'eva I.A. The future of territorial development strategies: analysis of modern methodologies. Regional Economics: Theory and Pactice. 2016;10(433):28-45. (In Russ.)]

17. BishopM.NewStateSpacesandContestedTerritories: ACriticalAnalysisofJointRegionalPlanningPanels. UrbanPolicy And Research. 2014;32(2):185-201.

18. Harrison J., Age S. When regions collide: in what sense a new 'regional problem'? Environment and planning A. 2014;46(10):2332-2352.

19. Johannesen E., Hoines A.S., Dolgov A.V.,Fossheim M. Demersal Fish Assemblages and Spatial Diversity Patterns in the Arctic-Atlantic Transition Zone in the Barents Sea. PLOS ONE.2012;7(4):e34924.

20. Purvis M., Grainger A.Exploring Sustainable Development: Geographical Perspectives.Earthscan; 2013. 416 p.

21.Zimmerbauer K. Constructing peripheral crossborder regions in planning: territory-network interplay in the Barents region. Environment and planning A.2014;46(11):2718-2734.

22. Bilorus O.G. Imperativi stalogo rozvitku v epokhu globalizatsiï. Zbirnik naukovikh prats' Vinnits'kogo natsional'nogo agrarnogo universitetu. Seriya: ekonomichni nauki. 2014;1(1):16-27. [Bilorus O.G. The Imperatives of Sustainable Development in the Age of Globalization. Collection of scientific works of Vinnytsa National Agrarian University. Series: Economic Sciences. 2014;1(1):16-27. (In Ukr.)]

23. Burkins'kii B.V. "Zelena" ekonomika kriz' prizmu transformatsiinikh zrushen' v Ukraïn. Odesa: IPREED NAN Ukraïni - Saki: PP "Pidpriemstvo Feniks"; 2015. 348 s. [Burkins'kii B.V. "Green" economy through the prism of transformational shifts in Ukraine. Odesa: IPREED NAN Ukraïn - Saki: PP "Pidpriemstvo Feniks"; 2015. 348 p. (In Ukr.)]

24. Ivanova T. L. Global'nii makroekonomichniindikatori stalogo rozvitku natsional'noï ekonomiki. Innovatsiina ekonomika. 2015;10(48):86-93.[Ivanova T. L. Global macroeconomic indicators of sustainable development of the national economy. Innovative economy. 2015;10(48):86-93. (In Ukr.)]

25. Soloshich I.O. "Zelena ekonomika" v konteksti zabezpechennya perekhodu Ukraïni do stalogo rozvitku. Ekonomichnii forum. 2016;28:30-36.[Soloshich I.O. "Green economy" in the context of ensuring Ukraine's transition to sustainable development. Economic forum. 2016;28:30-36. (In Ukr.)]

26. Agenda for the twenty-first century. Adopted by the United Nations Conference on Environment and Development, Rio de Janeiro, 3-14 June 1992. [Electronic resourse]. Available at: http://www.un.org/ru/documents/ decl_conv/conventions/pdf/agenda21.pdf (access date 29.10.2017).

27. Ofitsial'nyi sait Federal'noi sluzhby statistiki [Elektronnyi resurs]. Rezhim dostupa: http://www.gks.ru/ (data obrashcheniya 29.10.2017). [Official website of the Federal Statistical Service [Electronic resourse]. Available at: http://www.gks.ru/ (access date 29.10.2017). (In Russ.)]

\section{Сведения об авторах:}

Оборин Матвей Сергеевич - доктор экономических наук, профессор.

Шерешева Марина Юрьевна - доктор экономических наук, профессор.

Иванов Николай Александрович - аспирант, кафедра маркетинга.

Кожушкина Ирина Владимировна - аспирантка, кафедра финансов, кредита и мировой экономики.

Information about the authors:

Matvey S. Oborin - Dr. Sci. (Economics), Prof.

Marina Yu.Sheresheva - Dr. Sci. (Economics), Prof.

Nikolay A. Ivanov - Post-graduate student, Department of Marketing.

Irina V. Kozhushkina - Post-graduate student,, Department of Finance, Credit and World Economy,

\section{Конфликт интересов.}

Авторы заявляют об отсутствии конфликта интересов.

Поступила в редакцию 13.07.2017.

Принята в печать 23.08.2017.

\section{Conflict of interest.}

The authors declare no conflict of interest.

Received 13.07.2017.

Accepted for publication 23.08.2017. 